\title{
O DIREITO NATURAL REVIGORADO DE JOHN MITCHELL FINNIS
}

THE REVIGORATED NATURAL RIGHTS OF JOHN MITCHELL FINNIS

Adrian Sgarbi ${ }^{1}$

\begin{abstract}
Resumo:
A teoria do Direito Natural de John M. Finnis situa-se dentre as mais promissoras formulações do Direito Natural contemporâneo. Neste artigo, o Autor analisa os aspectos fundamentais desta construção sem perder de vista o contexto da teoria jurídica atual.
\end{abstract}

Palavras-chave: Teoria Geral do Direito. Direito Natural. Positivismo jurídico.

\begin{abstract}
:
The theory of Natural Rights by John M. Finnis is among the most promising interpretations of contemporary Natural Rights. In this article, the Author analyzes the fundamental construction of this theory without losing sight of the current context of judicial theory.
\end{abstract}

Keywords: General jurisprudence. Natural Rights. Legal Positivism.

Introdução

John M. Finnis faz parte da New School of Natural Law (juntamente com Germain Grisetz, Joseph Boyle, Robert P. George e Willian E. May) que, ao menos desde meados do século XX, tem realizado uma reinterpretação do pensamento de Santo Tomás de Aquino com o objetivo de promover uma revitalização do Direito Natural.

Evitando digressões sobre a história do Direito Natural, com o livro Lei Natural e Direitos Naturais, publicada no ano de 1980, Finnis, que foi aluno de Hart, procura em termos contemporâneos examinar o que se pode entender por "direitos naturais". Aliás, foi o próprio Hart que sugeriu o título desta obra que, iniciada em 1966, levou treze anos para ser completada.

Logo no Prefácio de LNDN, e em inúmeras ocasiões de seu texto, Finnis não apenas revela sua formação intelectual originária da Analytical Jurisprudence, mas também que durante suas investigações foi modificando seus pontos de vista. Começou "suspeitando que pudesse haver algo mais que superstição e obscuridade nas teorias do Direito Natural" e a reconhecer méritos em Platão, em Aristóteles e, sobretudo, em Santo

1 Doutor pela Faculdade de Direito da Universidade de São Paulo. Professor de Teoria Geral do Direito da Pontifícia Universidade Católica do Rio de Janeiro. 
Tomás de Aquino que, em seu entendimento, “ocupa um lugar estratégico único na história do pensamento jusnaturalista".

Assim, duas afirmações ecoam fortemente em LNDN. A primeira é invocativa da compreensão dos "bens humanos" que somente podem ser assegurados ou protegidos através de "instituições humanas"; a segunda é que existem certas exigências relativas à "razão prática" que apenas as "instituições humanas", tais como as "leis humanas", podem satisfazer. Globalmente consideradas, delas extrai Finnis a possibilidade de se distinguir entre o pensamento "correto", alusivo a atos "razoáveis" e os atos que "não são razoáveis", porque com ele contrastantes. Nesse conjunto, portanto, relevante é saber-se que "bens humanos" são esses e qual o papel da razão nisso tudo.

Para tanto, Finnis dialoga com inúmeros autores dos quais muitos fazem parte da tradição da filosofia analítica. Por assim dizer, dentre suas influências proeminentes, ainda que nem sempre para concordar, encontram-se nomes como Jeremy Bentham, John Austin, Hans Kelsen, Herbert L.A. Hart, Wesley N. Hohfeld e Lon L. Fuller, além das presenças de Aristóteles, Santo Tomás de Aquino e Max Weber.

1. Lei natural e direitos naturais (Primeira aproximação)

O professor John M. Finnis é conhecido por suas oposições ao modo pelo qual o Direito Natural vem sendo retratado de Bentham até, pelo menos, Joseph Raz, passando por Austin, Kelsen e Ross. Afirma, enfaticamente, que não conhece nenhum Autor do Direito Natural que tenha tangenciado essas "caricaturas". Assim, com base em Aristóteles e, sobretudo, em Santo Tomás de Aquino procura revigorar a teoria do Direito Natural, abandonando inúmeros aspectos da raiz analítica que durante muito tempo o acompanharam em seus estudos.

O livro Lei Natural e Direitos Naturais foi organizado em três partes. Aliás, conforme julga o próprio Autor, a Segunda Parte é a "medular", além de ser a mais extensa. Nela, o Leitor poderá constatar que estão compreendidos os Capítulos III até o XII, ambos incluídos. Portanto, a Primeira Parte contém os Capítulos I e II e a Terceira Parte tão-somente o Capítulo XIII.

Finnis entende ser a Segunda Parte medular porque nela temas relativos à ética filosófica, à filosofia política e à filosofia do direito são trabalhados de tal maneira que se apresentam intimamente relacionados. As outras partes são, assim, "complementares" porque a primeira contém tão-somente os supostos da investigação e a terceira foi tratada para encerrar o livro com considerações acerca das noções de "Natureza, Razão e Deus". 
Tudo considerado recomenda-se fortemente atenção aos Capítulos III (“Uma Forma Básica de Bem: O Conhecimento"), IV (“Os Outros Valores Básicos”) e V (“As Exigências Básicas da Razoabilidade Prática") em sua operacionalidade explicativa quando considerados conjuntamente com os Capítulos IX (“A Autoridade”), XI (“Obrigação”) e XII ("Leis Injustas").

\section{2. $\mathrm{O}$ ponto de partida de Finnis}

Finnis parte (nos mesmos termos que Grisetz) de construção, cujo propósito é o de demonstrar que a "Lei de Hume" (ou "falácia naturalística" como designou G.E. Moore em Principia Ethica, §12) não destrói os argumentos de Santo Tomás em sua formulação da doutrina do Direito Natural, percepção que, de fato, deve a Germain Grisez.

Como se sabe, Hume, no Tratado da Natureza Humana, afirmou a impossibilidade de se derivar de um ser um dever. Assim, Finnis, em contrapartida, pontua que Santo Tomás não assentou a teoria do Direito Natural na natureza humana em suas manifestações empíricas, mas sim no que veio a designar, ele, Finnis, de "princípios da razão prática". ${ }^{2}$ A diferença crucial é que esses princípios, longe de estarem calcados em deduções de algum fato encontram suporte na "auto-evidência". Auto-evidência porque, para alcançá-los é suficiente que se use a razão para acedê-los pelo intelecto, de tal modo que sequer cobrariam demonstração posterior. ${ }^{3}$ Ecoa fortemente aqui as palavras de Tomás de Aquino: «Deve-se fazer e buscar o bem; o mal deve ser evitado». ${ }^{4}$

Portanto, Santo Tomás de Aquino, aos olhos de Finnis, nunca incorreu na naturalistic fallacy, porque o "bom" e o "mau" não derivariam de fatores empíricos, mas destes "primeiros princípios".

No entanto, afirma Finnis, dada essa incompreensão, o Direito Natural foi severamente repudiado e até exposto de maneira caricatural. Assim o fizeram, acentua nosso Autor, Bentham, Austin, Kelsen, Hart e Raz. ${ }^{5}$

Para resolver este problema, desde as primeiras páginas de Lei Natural e Direitos Naturais (LNDN) sustenta que uma «moderna teoria do direito sugere, e a reflexão sobre a metodologia de qualquer ciência social confirma, que um teórico não

\footnotetext{
2 FINNIS, John Mitchell. Natural law and natural righs. Oxford: Oxford University Press, 1980. p. 34 e 68.

3 Id. Ibid., p. 33 e 67.

4 TOMÁS DE AQUINO, Santo. Summa Theológica. Madrid: Editorial Catolica, 1947-1960. q. 94, a.2.

5 FINNIS, John Mitchell. Natural law and natural righs. cit., p. 18 e 51.
} 
pode proporcionar uma análise e descrição 'teorética' dos fatos sociais a menos que também ele participe da tarefa de valorar, de compreender que é realmente bom para as pessoas humanas e que exige realmente a razoabilidade prática». ${ }^{6}$ Dessa maneira, Finnis destaca a necessidade de se assumir o "ponto de vista interno" (como Hart), isto é, não pode o teórico limitar-se ao ponto de vista do mero observador, neutro e avalorativo, pois uma adequada descrição requer a adoção do participante porque apenas ele terá condições para detectar qual é o "caso central” da realidade descrita.

Mas qual é o caso central identificado por aquele que assume o ponto de vista interno, o ponto de vista do participante, daquele que está inserido na prática e na convicção da prática?

Segundo Finnis, a resposta é a seguinte: deve-se eleger a atitude social que assuma o Direito como uma instituição que merece respeito e obediência, isto é, como exigência razoável para a consecução da felicidade e paz social. Para Finnis este ponto de vista moral pode ser designado com a seguinte expressão: "razoabilidade prática".

Mas o que é a "razoabilidade prática"?

Em termos, agora, apenas de explicitação do designado, pode-se dizer que com o vocábulo "razoabilidade" Finnis pretende demonstrar que o Direito é mais do que a lei, e que os valores não podem ser considerados tão-somente no âmbito da subjetividade dos indivíduos, porque, segundo afirma, são eles passíveis de uma discussão racional. Ou seja, para Finnis, todos os homens atuam movidos por valores, valores estes que podem ser explicados objetivamente (conseqüência de sua auto-evidência) e alcançados através da análise das próprias ações e instituições que os homens criam. Cumpre, assim, à teoria do Direito Natural estudá-los.

Por outro lado, com o termo "prática" pretende Finnis obter o efeito de assinalar a importância desta perspectiva para a Teoria do Direito, para esta potência explicativa que o teórico deve assumir, pois “prática” é «uma perspectiva de ação e decisão. Pensamento prático é pensar sobre o que (alguém deve) fazer». Daí que "razoabilidade prática expressa" «a razoabilidade ao decidir, ao assumir compromissos, ao eleger e executar projetos, e, em geral, de atuar». ${ }^{7}$

Anos mais tarde, no livro Fundamentals of Ethics, ano de 1983, Finnis afirma que a postura ética não consiste, simplesmente, em uma pergunta "pela ação", mas uma pergunta "para a ação", de tal modo que quem pergunta pela verdade na ética pretende obter demais de um conhecimento especulativo, um conhecimento sobre qual o

\footnotetext{
${ }^{6}$ FINNIS, John Mitchell. Natural law and natural righs. Oxford: Oxford University Press, 1980. p. 3 e 37.

7 Id. Ibid., p. 12 e 46.
} 
agir correto. ${ }^{8}$ Dessa forma, esses princípios para ação — que nos tornam pessoas melhores quando realizados - são conhecíveis, portanto, de um modo prático, isto é, através da percepção de quais são as boas razões que elegemos para o nosso agir. ${ }^{9}$ Sustenta a tese, assim, que este modo de operar de nossa inteligência como princípios para a ação é que se denomina "razão prática", e que estas razões últimas, que oferecidas pelo intelecto são possibilidades de nossa própria natureza são, enfim, aspectos de nosso bem-estar como pessoas.

\section{Casos centrais e casos periféricos}

Pode-se questionar, neste momento, qual o instrumento utilizado por Finnis para estudar essa prática. Invocando Aristóteles, nosso autor faz referência ao "significado focal", e afirma que ele torna possível apreender o significado do que é relevante designado acima de "caso central".

Aristóteles introduziu, estudou e empregou regularmente tal instrumento, também em sua filosofia dos assuntos humanos. Denominou-o identificação do significado focal (homonímia pros hen ou oph henos). Este instrumento é o correspondente a um importante componente de um instrumento metodológico de Max Weber, explicado sem demasiada clareza, o tipo-ideal. Implica em um abandono consciente do suposto em que, como vimos, Kelsen se baseava: que os termos descritivos ou explicativos devem ser empregados pelo teórico de tal maneira que se estendam, diretamente e no mesmo sentido, a todos os estados de coisas que, no discurso não-teorético, poderiam ser razoavelmente "chamados de direito", não-obstante o quão pouco desenvolvidos estes estados de coisas possam estar, e não obstante que estes estados de coisas dificilmente possam revelar algum interesse de seus autores (e.g. os "chefes despóticos") por diferenciar entre direito e força, direito e moral, direito e costume, direito e política, direito e discricionariedade absoluta, ou direito e qualquer outra coisa. ${ }^{10 / 11}$

Seguindo esta estratégia, Finnis diferencia os "casos centrais" dos "casos periféricos". Neste intento, diz que os positivistas erram quando ignoram a idéia do injusto, argumentando que essa valoração não importa ou-não é relevante.

\footnotetext{
8 FINNIS, John Mitchell. Fundamental of ethics. Georgetown: Georgetown University Press, 1983. p. 1.

9 Id. Ibid., p. 12.

10 L_ Ley natural y derechos naturales. Tradução de Cristóbal Orrego Sanches. Buenos Aires: AbeledoPerrot, 2000. p. 43-44;

11 . Natural law and natural righs. cit., p. 9-10.
} 
Assim, se o ponto central que se quer compreender é a amizade, ela é mais bem compreendida quando são analisadas as diversas situações sobre as quais se afirma haver amizade, tais como a "amizade entre noivos", "a amizade entre pessoas que se conhecem há muito tempo", a "amizade entre pessoas que acabaram de se conhecer". Ou seja, as situações de amizade tênue (ou amizade em sentido ampliado) auxiliam na intelecção da amizade "forte" (ou amizade em sentido restringido). Sua conclusão é a de que quem melhor adverte as situações de injustiça é aquele que melhor conhece a justiça.

Portanto, se exigências razoáveis são aquelas que promovem a felicidade e a paz social, o que mais tarde designará Finnis de "bem comum", então o "caso central do direito" são as leis que promovem o "bem comum", pois este referencial que determinará o que é uma "lei justa".

Desse modo, Finnis responde aos detratores do Direito Natural afirmando que eles não souberam compreender a teoria do Direito Natural. Porque «a obra teórica de cada um desses escritores (críticos do Direito Natural) estava controlada pela adoção, com fundamentos não explicitados e inadequadamente justificados, de algum ponto de vista prático como critério de relevância e significação para a construção de sua análise descritiva». ${ }^{12}$

Uma teoria sólida da lei natural é aquela que explicitamente, com plena consciência da situação metodológica descrita a pouco, empreende uma crítica aos pontos de vista práticos para distinguir o não-razoável do ponto de vista prático do razoável, e diferenciar o realmente importante do que não é importante ou somente é importante por sua oposição a, ou sua exploração não-razoável de o que é realmente importante. Uma teoria da lei natural pretende ser capaz de identificar as condições e princípios de retidão prática, de uma ordem boa e correta entre os homens na conduta individual. A menos que uma pretensão esteja assim justificada, a teoria analítica do Direito em particular e (pelo menos a maior parte de) todas as ciências sociais em geral não podem ter critérios criticamente justificados para a formação de conceitos gerais, e devem contentar-se com não mais que manifestações dos diversos conceitos próprios de determinados povos e/ou de determinados teóricos que se interessam por estes povos. ${ }^{13 / 14}$

${ }_{12}$ FINNIS, John Mitchell. Natural law and natural righs. Oxford: Oxford University Press, 1980. p. 18 e 51. . Ley natural y derechos naturales. cit., p. 51.

14 . Natural law and natural righs. p. 18. 
4. Pressupostos da teoria de Finnis

A teoria jurídica de John Finnis é fixada sob os auspícios de pressupostos os quais informam toda a sua construção. Pode-se dizer que eles são pressupostos de índole "valorativa", de índole "metodológica" e de inflexão "sócio-política". Esses pressupostos serão tratados separadamente nos três itens a seguir, de modo que assim possamos facilitar a exposição de seu pensamento: os "bens básicos" (plano valorativo); as "condições da razoabilidade prática" (plano metodológico); e as "relações entre comunidade e autoridade" (plano sócio-político).

\subsection{As formas de "florescimento" humano: os "bens básicos"}

Ponto de extrema relevância na obra de Finnis é a compreensão de "bens humanos" porque eles correspondem aos princípios mais gerais da "lei natural". Entretanto, o próprio Finnis parece oscilar um pouco com respeito à designação, pois tanto emprega a referida construção "bens humanos" quanto expressa a mesma idéia com a construção "formas de florescimento humano" (e, ainda, emprega, também de modo oscilante, os vocábulos "princípios", "bens", "bens básicos" e "valores").

Não-obstante, mantida a atenção voltada para o contexto, essa é uma oscilação designativa com considerável efeito esclarecedor caso se note que "florescer" é vocábulo que pode ser utilizado para destacar o tornar-se próspero. Dessa forma, ao recorrer a tal expressão o objetivo é pôr em destaque (ou destacar) as exigências para que esse "florescimento humano" se ultime.

Nesse sentido, nosso Autor afirma haver certas coisas que são básicas para o ser humano aprimorar-se; coisas, das quais, ele, o ser humano, depende, enfim, para desenvolver seu potencial crescimento enquanto ser humano. Por outras palavras, esses "valores básicos para a existência humana" constituem o substrato valorativo do homem em todos os seus juízos morais. Ou seja, os basic values de Finnis operam além de princípios de todo esforço moral, também do político e jurídico. Portanto, eles possuem caráter "prémoral", "pré-político" e "pré-jurídico". De todo modo, importa mais uma vez assinalar que para nosso Autor eles são "auto-evidentes", e mesmo que nem todos os homens os entendam e os realizem com igual intensidade, eles são universais e fundamentais.

Assim, Finnis fornece uma lista composta por sete bens (ou "valores" ou "princípios auto-evidentes") que todo homem ao fazer uso da razão ou da experiência 
pode conhecer. Esta lista, aliás, tem mantido estabilidade nos trabalhos de nosso Autor. ${ }^{15}$ São eles: o "conhecimento"; a "vida"; o "jogo"; a "experiência estética"; a "habilidade social ou amizade"; a "razoabilidade prática"; e a "religião".

(a) O "conhecimento": utilizado no sentido de "conhecimento especulativo", o "conhecimento" constitui um valor na medida em que é buscado "por si mesmo", e não instrumentalmente, ou seja, quando ele é útil para a consecução de outro objetivo. Portanto, o conhecimento pugnado por Finnis difere daquele que obtemos, por exemplo, para saber onde comprar o "pão tipo francês" mais gostoso do bairro ou, mesmo, o mais barato independentemente de ser gostoso ou-não. Tratase do conhecimento alusivo aos nossos desejos de saber por saber, nosso "interesse" da investigação pela investigação apenas pelo despertar de nossa curiosidade. ${ }^{16}$ Diz Finnis: «O exemplo de valor básico que se tem de examinar é o conhecimento. Quiçá seria mais preciso falar em conhecimento especulativo, utilizado aqui o termo especulativo não para fazer a distinção aristotélica entre o theoretike e o praktike, senão para distinguir o conhecimento enquanto buscado por si mesmo do conhecimento, enquanto buscado apenas instrumentalmente, isto é, enquanto seja útil na busca de um outro objetivo, tal como sobreviver, o poder, a popularidade, ou uma xícara de café a um bom preço». ${ }^{17}$

(b) A "vida": no sentido mais amplo do vocábulo ao ponto de mais bem ser compreendido na expressão "aspectos da vitalidade", o que engloba a própria preservação da vida (saúde corporal, cerebral, ausência de dor que sirva de presságio a algum mau funcionamento do organismo), bem como a busca do homem pela saúde. Portanto, os programas e as leis para a segurança das carreiras médicas, que incentivam a boa alimentação e aos programas de produção de alimentos saudáveis etc. Nesta categoria está, inclusive, presente o "impulso de copular" como gerador de vida. Afirma Finnis: «Certamente é tentador considerar a procriação como um valor básico distinto, irredutível, correspondente à inclinação a

${ }_{15}$ FINNIS, John Mitchell. Natural law and natural righs. Oxford: Oxford University Press, 1980. p. $59-75$ e 92-123; Fundamental of ethics. Georgetown: Georgetown University Press, 1983. p. 30-35. . Natural law and natural righs. cit., p. 60-62 e 92-93.

17 Id. Ibid., p. 59-60 e 91-92. 
gerar descendentes, reproduzir, criar (...). Podemos distinguir o desejo e a decisão de ter um filho, simplesmente por dá-lo à luz, do desejo e a decisão de cuidá-lo e de educá-lo. O primeiro desejo e decisão é uma busca do bem da vida, neste caso a-vida-em-sua-transmissão; os outros desejos e decisões são aspectos da busca dos distintos valores básicos da sociabilidade (ou amizade) e a da verdade (a-verdade-emsua-comunicação), que correm paralelos à busca contínua do valor da vida que está implicada no simples manter vivo o filho até que possa viver por si mesmo». ${ }^{18}$

(c) O "jogo": entendido como "importante e irredutível elemento da cultura humana", Finnis acentua sua relevância antropológica, porquanto esta prática pode ser ingressar em qualquer atividade humana. Conforme acentua, «cada um de nós pode notar o sentido de se ocupar com realizações (performances) que não têm outro sentido diferente da realização mesma que é desfrutada por si mesma». ${ }^{19}$

(d) A "experiência estética": corresponde à beleza entendida esta como própria da natureza ou decorrente da ação humana que é tanto experimentada pelo criador quanto pelo expectador. Por outras palavras, é a «experiência que se valora e que se encontra na criação e/ou na apreciação ativa de alguma obra de forma significativa e agradável». ${ }^{20}$

(e) A "sociabilidade ou amizade": segundo Finnis este bem básico "se realiza em sua forma mais fraca com um mínimo de paz e harmonia entre os homens, e que atravessa as formas de comunidade humana até sua forma mais forte com o florescimento da amizade plena». Ela implica em «obrar pelos propósitos do próprio amigo, pelo bem-estar do próprio amigo». ${ }^{21}$

(f) A "razoabilidade prática": entende Finnis ser este «o bem básico de ser capaz de fazer com o que a própria inteligência se aplique eficazmente (o raciocínio prático que resulta em uma ação) aos problemas de

\footnotetext{
${ }^{18}$ FINNIS, John Mitchell. Natural law and natural righs. Oxford: Oxford University Press, 1980. p. 86-87 e 117-118.

${ }^{19}$ Id. Ibid., p. 87).

${ }^{20}$ Id. Ibid., p. 87-88 e 119.

${ }^{21}$ Id. Ibid.
} 
eleger as ações e o estilo de vida de cada um e de formar o próprio caráter». Como tal, é um «valor complexo que implica liberdade e razão, integridade e autenticidade». Para Finnis, a razoabilidade prática apresenta um «aspecto interno, como quando alguém se esforça para conduzir as próprias emoções e disposições à harmonia de uma paz interior da mente que não é somente produto de drogas ou de doutrinamento nem mesmo constituem um mero convite à passividade; e um aspecto externo, como quando alguém se esforça por fazer que as próprias ações (que são exteriores quando mudam um estado de coisas no mundo e que muitas vezes afetam as relações entre as pessoas) sejam autênticas, é dizer, realizações genuínas de suas próprias valorações, preferências, esperanças e autodeterminações livremente ordenadas». ${ }^{22}$

(g) A "religião": por "religião" Finnis entende algo a ser determinado por cada um de nós, até mesmo se se crê em uma ordem universal ou se se assume uma postura agnóstica. Daí pondera que «Não é verdade que inclusive um Sartre, assumindo como seu 'ponto de partida' que Deus não existe (e que portanto "tudo está permitido"), considera não-obstante que ele é 'responsável' — está obrigado a atuar com liberdade e autenticidade, e a querer a liberdade de outras pessoas de igual modo que a sua própria - e que tem de o ser; e tudo isso porque, antes de qualquer escolha sua, 'o homem' é um ser livre? E não é este (não importa o quão residual seja) um reconhecimento de e uma preocupação por uma ordem de coisas 'mais além' de todos e de cada um dos homens? E assim, sem querer incorrer em nenhuma petição de princípio, não podemos para facilitar as coisas qualificar esta preocupação, que é uma preocupação por um bem que consiste em uma forma de ordem irredutivelmente distinta, como religiosa? ${ }^{23}$.

Além dos "bens básicos" serem "auto-evidentes" e apreensíveis pela técnica da atenção ao modo de operar de nossa inteligência, isto é, pela razão prática, Finnis faz outras tantas afirmações acerca deles, todas conexas a este caráter de "auto-evidência". A

\footnotetext{
${ }^{22}$ FINNIS, John Mitchell. Natural law and natural righs. Oxford: Oxford University Press, 1980. p. 88-89 e 120-121.

${ }^{23}$ Id. Ibid., p. 89-90 e 120-121.
} 
primeira é que eles são incomensuráveis. A segunda é que não existe qualquer hierarquia valorativa entre eles.

Considerando a primeira observação, de fato Finnis reconhece que a lista dos bens básicos que fornece não é exaustiva. Entretanto, afirma que as outras formas de bens são maneiras ou combinações de maneiras de se buscar e de realizar uma das sete formas básicas anteriormente referidas. Reconhece também que há infindáveis aspectos da autodeterminação e da auto-realização humanas à parte do que foi enumerado, tais como a coragem, a generosidade, a moderação, a amabilidade etc. Mas, ainda assim, afirma Finnis, eles não são bens básicos, mas maneiras, meios ou modos de se obter os valores básicos, porquanto capacitam os indivíduos a buscá-los. ${ }^{24}$ Sendo assim, Finnis expressa em que sentido esses valores podem ser considerados "básicos": «Em primeiro lugar, cada um é uma forma de bem igualmente evidente. Em segundo lugar, nenhum deles pode ser reduzido analiticamente a ser um aspecto de algum dos outros. Em terceiro lugar, cada um, quando nos concentramos neles, pode ser razoavelmente considerado o mais importante». ${ }^{25}$

Das asserções enunciadas, nosso Autor formula a segunda observação: a de que não existe qualquer hierarquia objetiva aferível entre esses valores designados de bens básicos, pois eles são igualmente fundamentais. Essa a sua afirmação: «Cada um é fundamental. Nenhum é mais fundamental que qualquer dos outros, porque em cada um deles cabe razoavelmente centrar a atenção, e cada um, quando se focaliza nele a atenção, reclama um valor prioritário. Dai que não há uma prioridade objetiva de valor entre eles». ${ }^{26}$ A síntese é que se bem não exista qualquer hierarquia objetiva entre eles é possível que cada pessoa os estime de maneira diferente (campo subjetivo das avaliações), mas isto é explicável em razão do temperamento de cada um, das oportunidades que tenha tido na vida e a capacidade de cada pessoa concreta.

\section{As exigências da razoabilidade prática}

Conforme se pôde depreender da construção teórica de Finnis, a "razoabilidade prática" é um bem. Como vimos, «o bem básico de ser capaz de fazer que a própria inteligência se aplique eficazmente (o raciocínio prático que resulta em

\footnotetext{
${ }^{24}$ FINNIS, John Mitchell. Natural law and natural righs. Oxford: Oxford University Press, 1980. p. 90-92 e 121-122.

25 Id. Ibid., p. 92 e 123.

${ }^{26}$ Grifo do original. Id. Ibid. p. 93-94 e 124.
} 
uma ação) aos problemas de eleger as ações e o estilo de vida de cada um e de formar o próprio caráter».

Todavia, a razoabilidade prática desempenha claramente um papel dual, pois além de um "bem humano", ela constitui, para nosso Autor, um processo de raciocínio que possibilita distinguir o pensamento prático correto do pensamento prático incorreto, a partir do qual se torna possível, em termos últimos, avaliar os atos humanos que são razoáveis dos atos que não são razoáveis.

Dessa forma, aquele que em seu viver vive à altura dessas exigências é, por isso mesmo, um homem moralmente bom, de tal modo que a razoabilidade prática consiste em um conjunto de exigências metodológicas para esse reconhecimento. A razoabilidade prática, assim, é a "viga mestra" que possibilita sejam os outros valores básicos sustentados sobre uma mesma estrutura e a operarem com o mesmo propósito, o bem-estar pessoal. Tudo isso foi enunciado por Finnis, em 1987, através do "primeiro princípio da moralidade": «Deve-se eleger e querer aquelas e apenas aquelas possibilidades cujo desejo seja compatível com o desenvolvimento humano integral». ${ }^{27}$

Mas o que foi dito não implica que seja a razoabilidade prática o único valor nem tampouco o mais importante dos valores básicos, pois seu propósito não é ser razoável sem outras referências, mas fazer com que os demais bens de nossa personalidade tenham o devido desenvolvimento. Segundo Finnis, a razoabilidade prática, no momento de nossa ação, não sugere apenas que tenhamos um fim ou propósito, mas que utilizemos um critério nesta ação. Portanto, o agir moral se distingue do agir imoral no "modo" pelo qual buscamos os bens básicos, de maneira que a perseguição de um bem humano não se configure apenas como uma imposição da razoabilidade, mas também é preciso que se o faça moralmente. Daí que, por assim dizer, dado o fato de o "primeiro principio da moralidade" ser sobremaneira genérico, impõe-se articulá-lo com guias mais precisos para que assuma feição pragmaticamente útil às circunstâncias concretas. Propõe Finnis nove condições ou exigências metodológicas mais precisas consignando serem determinações da razoabilidade prática à nossa ação moral.

A primeira, é que devemos ter um plano de vida racional.

(...) "deveríamos recordar que, ainda que correspondam a impulsos e inclinações que podem se fazer sentir com anterioridade a qualquer consideração inteligente sobre o que merece a pena buscar, os aspectos básicos do bem estar humano somente são realizáveis por quem dirige, atende e controla os seus instintos, inclinações

${ }^{27}$ FINNIS, John Mitchell; GRISEZ, Germaine; BOYLE, Joseph. Nuclear derretance, morality and realism. Oxford: Claredon Press, 1987. p. 283. 
e impulsos, de maneira inteligente. Em sua forma mais completa, portanto, a primeira exigência da razoabilidade prática é o que John Rawls chama um plano de vida racional". ${ }^{28}$

A segunda, é que devemos prestar atenção aos bens básicos sem descartar qualquer um, isto é, sem ser arbitrário em alguma preferência. Porque embora um plano de vida importe em priorizar algumas das formas básicas de bem, para que a opção seja racional devem ser consideradas as capacidades, circunstâncias e gostos sem se incorrer em qualquer sobrevalorização.

Qualquer compromisso com um plano de vida coerente implica em algum grau de concentração em uma ou algumas das formas básicas de bem, temporal ou permanentemente, de outras formas de bem.

Porém, o compromisso será racional somente se se baseia na valoração por cada uma de suas próprias capacidades, circunstâncias, e ainda de seus gostos. Será irrazoavelmente se se baseia na desvalorização de qualquer das formas básicas de excelência humana, ou se se baseia em uma sobrevalorização desses bens meramente derivados ou complementarmente secundários e condicionalmente valiosos como a reputação ou (em um sentido diferente de secundariedade) o prazer. $^{29}$

A terceira exigência é que não se deve nutrir um tratamento preferencial arbitrário entre as pessoas. A "regra de ouro" para vencer a hipocrisia, a indiferença e o egoísmo e submeter nossos atos ao teste universal dos nossos juízos morais ao enunciado "Faças aos outros, o que gostarias que fizessem a ti".

A sobrevivência de outra pessoa, sua aquisição de conhecimentos, sua criatividade, sua plena realização, podem não me interessar, podem não me preocupar, podem estar além do alcance de meu poder. Porém tenho eu alguma razão para negar que são realmente bens, ou que são objetos dignos de interesse, a preocupação a favor desse homem e de todos os que têm que ver com ele? (...) "Faça aos outros o que gostarias que fizessem a ti". "Coloque os sapatos de seu próximo". "Não condenes aos outros pelo que você mesmo está desejoso de fazer". "Não impeças (sem uma razão especial) os outros de conseguir para si mesmos o que você está querendo conseguir para ti”. Estas são exigências da razão, porque ignorá-las é ser arbitrário entre os diversos indivíduos. ${ }^{30}$

\footnotetext{
${ }^{28}$ FINNIS, John Mitchell. Ley natural y derechos naturales. Tradução de Cristóbal Orrego Sanches. Buenos Aires: Abeledo-Perrot, 2000. p. 134; Natural law and natural righs. Oxford: Oxford University Press, 1980. p. 103.

${ }^{29}$ Id. Ibid., p. 136; Id. Ibid., p. 105.

${ }^{30}$ Id. Ibid., p. 138; Id. Ibid., p. 107-108.
} 
A quarta é que se deve estar aberto a todas as formas básicas de bens em todas as circunstâncias de mudança da vida. Com isso, afasta-se o pensamento daquele que se sente privado de sentido de vida quando um projeto ou plano fracassa.

Com o fim de estar suficientemente abertos a todas as formas básicas de bem e todas as mudanças circunstanciais ao longo da vida, e em todas as relações, freqüentemente imprevisíveis, de cada um com outras pessoas, e em todas as oportunidades que cada um tem de proporcionar o bem-estar dos demais ou de aliviar os infortúnios, deve-se ter certo desprendimento com respeito a todos os projetos específicos e limitados que se assume. ${ }^{31}$

A quinta corresponde ao compromisso que se deve ter quando se assume um projeto. Porque ao ter este compromisso, evita-se que eles sejam abandonados facilmente.

A quinta exigência estabelece o equilíbrio entre o fanatismo e o desejo, a apatia, a omissão irrazoável ou o rechaço de "ver-se comprometido" com qualquer coisa. É simplesmente a exigência de que uma vez assumidos os próprios compromissos gerais não se deve abandoná-los precipitadamente (porque isso significaria, no caso extremo, que nunca se lograria participar realmente de algum dos valores básicos). ${ }^{32}$

A sexta cobra ações idôneas à realização dos propósitos.

A sexta exigência tem óbvias conexões com a quinta, porém introduzem um nosso campo de problemas para a razão prática, problemas que rumam ao coração da "moral". Porque se trata da exigência de que se cause bem ao mundo (em sua própria vida e na vida das demais pessoas) mediante ações que sejam eficientes para se alcançar seus propósitos (razoáveis). Não se devem desperdiçar as próprias oportunidades com métodos ineficientes. As ações de cada um devem ser julgadas por sua efetividade, por sua adequação ao seu propósito, por sua utilidade, por suas conseqüências. ${ }^{33}$

A sétima exige respeito a todos os valores básicos em cada ato, o que constitui, para Finnis, a base para que se possa sustentar a estrita inviolabilidade dos direitos humanos básicos.

A sétima exigência da razoabilidade prática pode formular-se de diversas maneiras. Uma delas é que não se deve realizar nenhum ato que de sua realização não

\footnotetext{
31 FINNIS, John Mitchell. Ley natural y derechos naturales. Tradução de Cristóbal Orrego Sanches. Buenos Aires: Abeledo-Perrot, 2000. p. 103; . Natural law and natural righs. Oxford: Oxford University Press, 1980. p. 109-110.

32 Id. Ibid., 140-141; Id. Ibid.

33 Id. Ibid.; Id. Ibid.
} 
se faz mais que dar ou impedir a realização de ou participação em uma ou mais formas básicas de bem humano. ${ }^{34}$

A oitava, são as exigências do bem comum.

Muitíssimas, quiçá inclusive a maioria, de nossas responsabilidades, obrigações e deveres morais concretos, têm sua base na oitava exigência. Podemos denominá-la de exigência de favorecer e promover o bem comum das próprias comunidades. ${ }^{35}$

A nona, e última, exigência é a de que se deve seguir a própria consciência.

A nona exigência poderia ser considerada com um aspecto particular da sétima (que nenhum bem básico pode ser atacado diretamente por nenhum ato), ou inclusive como um resumo de todas as exigências. Porém, ela é bastante característica. É a exigência de que não se deve fazer o que se julga ou pensa ou "sente" em definitivo que não se deve fazer. É dizer, deve-se "atuar de acordo com a própria consciência". ${ }^{36}$

Embora se possam considerar essas exigências da razoabilidade prática em separado, Finnis faz questão de assentar que elas se encontram inter-relacionadas. Portanto, se se quiser alcançar realizações morais ou um desejo razoável é imprescindível que se recorra a esses princípios metodológicos, demais dos bens básicos ou princípios substantivos.

Igualmente afirma Finnis que cada uma das exigências destacadas pode ser pensada como um modo de obrigação moral ou de responsabilidade, tendo em vista que cada uma delas desempenha sua parte na razoabilidade prática ao gerar argumentos, tais como: «1. A harmonia entre propósitos/ o reconhecimento de bens/ a ausência de arbitrariedade entre as pessoas/o desprendimento com respeito a realizações particulares do bem/ a fidelidade dos compromissos/ a eficiência na esfera técnica/ o respeito por cada valor básico a atuar/ a comunidade/ a autenticidade para seguir a própria razão... são (todos) aspectos do verdadeiro bem básico da liberdade e da razão; 2. Que a harmonia entre propósitos, ou..., em tais-e-quais circunstâncias pode ser conseguida/ realizada/ expressada/ etc. somente (ou melhor, ou de maneira mais adequada) (não) realizado o ato; portanto 3. O ato (não) devia/ (não) tem que/ (não) deve... ser realizado». ${ }^{37}$

\footnotetext{
${ }^{34}$ FINNIS, John Mitchell. Ley natural y derechos naturales. Tradução de Cristóbal Orrego Sanches. Buenos Aires: Abeledo-Perrot, 2000. p. 148; Press, 1980. p. 118-119.

35 Id. Ibid., p. 154; Id. Ibid. p. 125.

${ }^{36}$ Id. Ibid., p. 140-141; Id. Ibid., p. 109-110.

${ }^{37}$ FINNIS, John Mitchell. Natural law and natural righs. cit., p. 126-127 e 125.
} 
Em resumo, à vista dos nove pontos destacados acima, conclui-se que a moralidade, entendida à moda de Finnis como respeito e promoção do bem-estar humano, contribui, por um lado, para a organização do plano de vida: condição ou exigência 1 combinada com as condições ou exigências 3, 4 e 5; e, por outro lado, para a atuação intersubjetiva, isto é, do "eu" com o "outro": condições ou exigências 2, 6, 7 e 8. Finalmente, a condição 9 implica em se considerar nestes planos a autonomia ou a capacidade de escolha crítica do agente da ação, enfim, uma consciência do agir.

6. Comunidade e autoridade

A construção de Finnis, demais de consignar os "bens humanos básicos" como "pressupostos valorativos" e de afirmar certas exigências de razoabilidade prática como "pressupostos metodológicos", traz a relação entre "comunidade e autoridade" como instâncias de sociabilidade e de comando, isto é, como "pressupostos sócio-políticos", o que implica em se estabelecer certas digressões, sobretudo, a respeito do papel do Estado. Neste momento, os Capítulos VI (“Comunidade, Comunidades, Bem-comum”) e IX (“A Autoridade") de "Lei Natural e Direitos Naturais" são de expressiva importância.

A «comunidade humana...», para Finnis, sob o ponto de vista da razoabilidade prática, «...é primeiramente uma questão de comunidade enquanto ordem». ${ }^{38}$ Mas há uma complexidade de coisas presentes em nossa fala quando colocamos em consideração a conexão entre os princípios básicos especificados por nosso Autor e a ordem em seu conjunto.

Em primeiro lugar, a ordem que não produzimos como a ordem estudada pelas ciências naturais.

Em segundo lugar, a ordem que podemos introduzir como a ordem estudada pela lógica, pela epistemologia, metodologia e outras ciências afins, pois, «Parte de nossa unidade na comunidade humana é unidade de inteligência em suas capacidades, suas operações e seu produto, o conhecimento». ${ }^{39}$

Em terceiro lugar, a ordem que introduzimos (ou, mesmo, impomos) em qualquer assunto que esteja na esfera de nosso poder, tais como: a cozinha, a construção naval, a navegação etc..

\footnotetext{
${ }^{38}$ FINNIS, John Mitchell. Natural law and natural righs. Oxford: Oxford University Press, 1980. p. 140-141 e 169.

${ }^{39}$ Id. Ibid., p. 140 e 168.
} 
Em quarto lugar, a ordem que nós introduzimos em nossas próprias ações através da inteligente deliberação e eleição; ordem esta que é estudada pela psicologia, pela biologia, pela história dos assuntos humanos, ética e filosofia política.

A partir dessas considerações, Finnis estabelece seus respectivos paralelos com a unidade familiar. ${ }^{40}$

Quanto à primeira observação, afirma que «Uma familia tem uma especial unidade física de inter-relação genética próxima, relações sexuais entre os pais, a alimentação dos filhos não nascidos do corpo da mãe, certo grau de compatibilidade de grupos sangüineos e de tecidos, semelhanças herdadas de aparência corporal e quiçá de sentimentos, temperamento, inteligência...». ${ }^{41}$ Da segunda observação, diz que «Uma família pode ter uma especial unidade desta ordem de relações na medida em que seus membros pensam e aprendem juntos, adquirindo um fundo comum de experiências e intuição, e, inclusive, sabendo quanto sabem os outros...»..$^{42} \mathrm{Da}$ terceira, que «Uma família pode ter uma especial unidade nesta ordem de relações, na medida em que seus membros compartilham não apenas a casa, propriedade e posses, senão também uma gama de modos especialmente sutis de comunicação uns com os outros...»..$^{43} \mathrm{E}$, por fim, que «Uma família pode ter uma especial unidade nesta ordem de relações, na medida em que cada um de seus membros (especialmente os que dirigem e que dão forma à vida em comum) se dedica a encontrar sua própria plenitude (pelo menos em parte) na ajuda de outros membros a se realizarem por si mesmos, cuidando deles e ajudandoos a acreditar na liberdade e responsabilidade e em outros aspectos básicos da plena realização humana». ${ }^{4}$

Entretanto, nota que, das quatro ordens anteriormente referidas, a razoabilidade prática é primariamente uma questão de comunidade na quarta ordem. Contudo, para resolver os problemas de interação e coordenação na comunidade não há mais do que duas alternativas: unanimidade e autoridade. ${ }^{45}$

Entende Finnis, «A unanimidade está particularmente fora do alcance do que de fato é possível na comunidade politica», ${ }^{46}$ pois ela «não é uma possibilidade

\footnotetext{
${ }^{40}$ FINNIS, John Mitchell. Natural law and natural righs. Oxford: Oxford University Press, 1980. p. 139-141 e 167-169 e 139-141.

${ }^{41}$ Id. Ibid., p. 139 e 167.

${ }^{42}$ Id. Ibid.

${ }^{43}$ Id. Ibid., p. 140 e 168.

${ }^{44}$ Id. Ibid., p. 139-140 e 168-169.

${ }^{45}$ Id. Ibid., p. 232 e 262.

${ }^{46}$ Id. Ibid., p. 232-233 e 262-263.
} 
prática em uma comunidade em que a inteligência e a dedicação ao bem-comum estão mescladas com o egoísmo e a estupidez».47

Com respeito à "autoridade", Finnis procura expor os "sentidos" com os quais o termo pode ser enunciado. Ou seja, nosso autor pontua que a expressão « $\boldsymbol{X}$ tem autoridade sobre $S$ » pode ser explicado ao menos sob três perspectivas distintas:

(1) Sentido 1: Quando $\boldsymbol{S}$ o diz, isto é, quando $\boldsymbol{S}$ admite que $\boldsymbol{X}$ tem autoridade;

(2) Sentido 2: Quando um $\boldsymbol{Z}$ o diz a um $\boldsymbol{Q}$ com respeito a $\boldsymbol{X}$ e $\boldsymbol{S}$;

(3) Sentido 3: Quando $\boldsymbol{Z}$ conhece bem as razões de $\boldsymbol{S}$ em razão de alguma condição que tem.

Na primeira situação, tem-se a descrição de "um ponto de vista interno"; na segunda situação uma descrição da autoridade sob o ponto de vista externo; na terceira, o ponto de vista técnico ou profissional. Em que pese essas variações, nosso Autor assinala que o ponto de vista que assume para descrever a relação de autoridade é o primeiro, pois os outros dois são apenas conseqüências deste.

Pode-se perguntar, por conseguinte, considerando que a obrigatoriedade da lei positiva encontra-se vinculada à autoridade política, quem são os legítimos titulares dessa autoridade. A resposta de Finnis é consideravelmente realista, pois diz que a autoridade em uma comunidade é legitimamente exercida pelos agentes que podem faticamente resolver os problemas de coordenação desta comunidade.

A autoridade (e, por conseguinte a responsabilidade de governar) em uma comunidade tem de ser exercida por aqueles que de fato podem resolver eficazmente os problemas de coordenação desta comunidade. Este princípio não é a última palavra sobre as exigências da razoabilidade prática relativa à atribuição ou ao reconhecimento da autoridade; porém, é a primeira e a mais fundamental. ${ }^{48}$

Entretanto, nosso Autor não deixa esta afirmação livre de maneirismos, porquanto acentua que a autoridade do governante encontra-se ancorada na responsabilidade de zelar pelo bem-comum através de prescrições de soluções normativas.

O fato de que a palavra empenhada por determinada pessoa ou organismo ou grupo de pessoas de fato seja acatada, de uma maneira geral, ou se atuará com base nela,

\footnotetext{
${ }^{47}$ FINNIS, John Mitchell. Natural law and natural righs. Oxford: Oxford University Press, 1980. p. 233 e 263.

${ }^{48}$ FINNIS, John Mitchell. Ley natural y derechos naturales. Tradução de Cristóbal Orrego Sanches. Buenos Aires: Abeledo-Perrot, 2000. p. 274;

Press, 1980. p. 246. Natural law and natural righs. Oxford: Oxford University
} 
tem conseqüências normativas para a razoabilidade prática; afeta as responsabilidades tanto do governante como do governado, ao criar certas razões excludentes para a ação. Estas conseqüências normativas derivam de um princípio normativo que a autoridade é um bem (porque dela se necessita para a realização do bem-comum) quando este princípio é considerado conjuntamente com o fato de que uma determinada pessoa, organismo, ou grupo de pessoas pode fazer para uma comunidade determinada, em um tempo determinado, o que a autoridade tem que fazer (isto é, assegurar e promover o bem-comum) ${ }^{49}$

Por outras palavras, a leitura fática correspondente à possibilidade de coordenar a ação da comunidade para o bem-comum é que, em última análise, obriga aos membros da comunidade a reconhecer a autoridade e de obedecer às leis que porventura venha instituir para este fim. Mas, caso a autoridade desconheça em seus atos esse seu propósito, diz nosso Autor que ela não pode esperar obediência.

Alguém que usa sua oportunidade empírica, ou inclusive a autoridade juridicamente reconhecida, para promover projetos totalmente opostos à razoabilidade prática não pode logo pretender razoavelmente que tenha cumprido com suas responsabilidades de acordo com a razão, e pode ser capaz de justificar sua pretensão de ter criado uma razão excludente boa e suficiente que afete as responsabilidades daqueles cujo acatamento busca ou exige. ${ }^{50}$

De todo modo, entende Finnis que compete à ciência política examinar «as condições empíricas sob as quais determinadas pessoas, organismos, ou grupo de pessoas podem criar diretrizes para a ação, com eficácia empírica». ${ }^{51}$

\section{Leis injustas e a obrigação moral de obedecer ao Direito}

Relativamente a tudo o quanto foi analisado importa, neste momento, questionar: como Finnis explica a obrigação jurídica? As normas jurídicas injustas são obrigatórias? Como a obrigação jurídica cria uma obrigação moral? Qual o parâmetro de Finnis quanto a estas questões?

Para responder a essas questões parece ser mais interessante começar pelo fim. Finnis sustenta que toda e qualquer obrigação deve ser explicada a partir do referencial da "razoabilidade prática". Portanto, algo é obrigatório quando este algo apresenta ao

\footnotetext{
${ }^{49}$ FINNIS, John Mitchell. Ley natural y derechos naturales. Tradução de Cristóbal Orrego Sanches. Buenos Aires: Abeledo-Perrot, 2000. p. 274; Press, 1980. p. 246. . Natural law and natural righs. Oxford: Oxford University

${ }^{50}$ Id. Ibid.; Id. Ibid.

${ }^{51}$ FINNIS, John Mitchell. Natural law and natural righs. cit., p. 244-245 e 274.
} 
sujeito da ação uma boa razão para agir conforme é preceituado, e não de outro modo. Para completar essa explicação deve-se avançar, agora, nos outros pontos.

Toda a construção teórica de Finnis encontra-se ancorada na consideração de que o vínculo entre "Direito" e "Moral" dá-se através da razoabilidade prática. O Direito é necessário porque há certos valores e determinadas exigências que apenas por intermédio dele podem ser vividos.

Assim o entende Finnis, as normas jurídicas constituem o que há de mais importante no Direito, porque são elas que estatuem o devido e o que não é devido positivamente. Portanto, elas se encontram no centro da discussão teórico-jurídica. Nãoobstante, elas, as normas, necessitam do teórico de uma análise mais profunda, pois elas devem passar, sempre, pelo crivo da avaliação da razoabilidade prática. É essa avaliação favorável que as habilita a assumir este caráter central como objeto de estudo. Isso porque o Direito não é para nosso Autor apenas exercício de poder, mas exercício de racionalidade.

Para embasar esta asserção, consigna Finnis, por um lado, que existem certos preceitos legais que são moralmente obrigatórios, tais como o respeito aos mais velhos. Nestes casos, a conduta é obrigatória mesmo que não haja uma lei positiva que a sancione. Por outro lado, diz existir normas que, embora não sejam moralmente obrigatórias foram previstas pelo legislador, como as normas relativas ao tráfego de carros nas vias urbanas. Sendo assim, questiona por qual razão cumprimos determinações que não foram estatuídas como obrigatoriamente impostas ou, por outras palavras, sancionadas pelas autoridades políticas. Sua resposta é que essas normas derivam diretamente do princípio da razão prática e ela nos determina que contribuamos para a consecução do bem-comum.

Evidentemente, que com esses termos passa a ser relevante a compreensão de "bem-comum". Por "bem-comum" Finnis reconhece "todos os bens básicos" (a vitalidade, a liberdade de avaliar a conduta, o conhecimento, a experiência estética, a amizade e sociabilidade, diversão e religião), assim como a garantia de um conjunto de condições materiais que tendem a favorecer cada indivíduo a desenvolver as formas básicas em sua esfera na comunidade. Aqui se encontra a chave para a compreensão das "leis injustas" na formulação de Finnis. Porque se o fundamento da obediência das normas ancora-se na sua razoabilidade para instituir o bem-comum, sempre se poderá perguntar o que fazer com uma lei instituída pela autoridade política que descumpre a esta determinação da razoabilidade prática. A resposta de Finnis é que, neste caso, encontra-se justificado o ato de descumprir as leis injustas, dado que elas não possuem autoridade moral. Este o esquema proposto por Finnis para explicar o ponto: 
Passo A: Temos que ser cumpridores do Direito em razão do bem-comum.

Passo B: Quando um padrão de conduta é estabelecido como obrigatório, o único modo de cumprir o Direito é fazendo.

Passo C: Portanto, temos que fazer onde tem sido legalmente estipulado como sendo obrigatório.

Abordando a questão de outro modo, mas pelo mesmo flanco argumentativo, pode-se dizer que para Finnis as normas jurídicas encontram-se necessariamente jungidas ao seu mérito para comandar condutas segundo a avaliação de conteúdo que pode fazer à luz da razoabilidade prática (o bem-comum), e não pela simples aferição de validade com base nos critérios formais estabelecidos pela ordem jurídica qua tale. Isso porque, uma norma válida formalmente pode ser questionada em sua força para comandar por ser injusta, de tal modo que ela poderá não ser aplicada seja total ou, mesmo, parcialmente. Concluindo, o ato da vontade política do legislador tem significado para a razoabilidade prática dos destinatários apenas dentro do marco normativo da razoabilidade prática, o qual não pode ser posto por ele, pelo legislador, e é este marco que estabelece os limites da obediência ao Direito.

Quanto a isso, Finnis tem apontado quatro razões objetivas para se considerar uma lei injusta: $1^{\text {a }}$ ) Quando ao invés de favorecerem o bem-comum elas buscam a realização de interesses privados; $2^{\mathrm{a}}$ ) Quando há abuso da autoridade dos funcionários da ordem jurídica, sejam eles agentes judiciais ou de vigilância; $3^{\mathrm{a}}$ ) Quando não se trata os sujeitos com igual consideração; $4^{\mathrm{a}}$ ) Por razões de justiça distributiva, quando se busca o próprio benefício através das funções públicas ou qualquer atividade que altere a distribuição justa entre os participantes. ${ }^{52}$ De todo modo, diz Finnis que apesar de tais injustiças práticas isso não significa que as leis que as estabeleçam não existam do ponto de vista técnico ou, mesmo, conforme os padrões formais da ordem jurídica. Daí que nada impede de se afirmar que uma lei injusta é lei, mas que não é obrigatória moralmente. Nestes casos pode haver como conseqüência a desobediência generalizada. Aqui, Finnis se distancia de Aquino, porquanto este consigna claramente que «lex injustia non est lex». ${ }^{53}$

Em suma, para Finnis, os princípios do Direito Natural consistem em dados bastantes para não apenas explicar a força obrigatória das leis, mas também para desobedecer-lhe. Isso significa que a obrigatoriedade moral de agir incluirá as normas jurídicas na medida em que elas sejam necessárias para a consecução do bem-comum. Nesse sentido, o governante não desfruta do "direito de ser obedecido", mas possui a

\footnotetext{
${ }_{52}$ FINNIS, John Mitchell. Natural law and natural righs. Oxford: Oxford University Press, 1980. p. 380-381.

${ }^{53}$ Id. Ibid., p. 363-366 e 390-393.
} 
condição coordenadora para orientar e produzir leis que sejam moralmente obrigatórias, isto é, ele é "autoridade" ou está dotado de "autoridade" na medida em que estabelece diretivas para promover e para proteger o bem-comum, de modo que quando assim agir produzirá, por conseqüência, a obrigação moral de obediência; em sentido oposto, não produzirá tal efeito.

\section{O Estado e a imposição de sanções}

Mantido o foco para o quanto foi assentado, os sete "bens básicos" (a vida, o conhecimento, o jogo, a experiência estética, a sociabilidade e a amizade, a religião e a razoabilidade prática) são reputados de "bens comuns" porque eles são valorados como "bens básicos" pelos membros da comunidade.

À vista disso, considerando-se que o papel do Estado é o de promover a coordenação entre ações humanas e os fins, a partir dos quais as pessoas encontram as condições necessárias para se alcançar um bem-básico (para os quais concorre a exigência de que se realize o bem comum), as regras estabelecidas pelas autoridades políticas que atendem a essas condições últimas devem poder ser impostas para que se escape da mera preferência pessoal por seu cumprimento. ${ }^{54}$

O parágrafo anterior, no entanto, esconde uma pretensão específica em Finnis. É que quando o Estado impõe sanções para os recalcitrantes em obedecer ao direito (no sentido finnisiano de conjunto de disposições que atendem ao bem-comum) ele, o Estado, está a impedir, aplicando castigos, que se ultime alguma vantagem indevida obtida pelo delinqüente sobre os demais membros da comunidade, já que estes limitaram suas eleições pessoais de agir. Ou seja, as sanções jurídicas para Finnis correspondem a instrumentos de "compensação" da referida vantagem, tendo em vista que a sanção representa um preceito de justiça geral. Mas não apenas isso. Quando uma sanção é infligida, guarda-se o propósito final de, com ela, buscar-se imprimir razoabilidade nas próximas ações do delinqüente, com o que se evidencia seu propósito educacional.

Tudo considerado, na literatura finissiana as sanções penais satisfazem a sociedade compensando-a da desobediência do delinqüente, ao mesmo tempo em que promove, em consideração última, o próprio bem-comum dado que educa o delinqüente para que zele por esse bem em seus próximos atos, tornando, por conseguinte, viável a vida em comunidade. A sanção é instrumento de restauração social e instância de reflexão para que eleições conseqüentes de ações não-superficiais (aquelas que prejudicam aos

\footnotetext{
${ }^{54}$ FINNIS, John Mitchell. Natural law and natural righs. Oxford: Oxford University Press, 1980. p. 351 e 379.
} 
outros) sejam tomadas, tornando, assim, os infratores pessoas mais razoáveis, pessoas que pautam a vida de modo bom e útil.

9. “Bem-comum", "justiça”, “direitos humanos”

Por "bem-comum", já o vimos, Finnis reconhece "todos os bens básicos" (a vitalidade, a liberdade de avaliar a conduta, o conhecimento, a experiência estética, a amizade e sociabilidade, diversão e religião), assim como a garantia de um conjunto de condições materiais que tendem a favorecer cada indivíduo a desenvolver as formas básicas em sua esfera na comunidade. Nesses termos, o "bem-comum" passa a ser o "objeto de toda a justiça".

A “justiça”, segundo Finnis, cumpre regular o «como uma pessoa deve tratar a outra (ou que direito tem uma pessoa de tratar a outra)». Assim, não é de se estranhar que as notas características da justiça encontrem associação com a razoabilidade prática, pois ela implica em considerar os bens básicos que a pessoa deve realizar e respeitar em comunidade. São elas: a "intersubjetividade"; o "dever"; e a "igualdade".

A nota característica da "intersubjetividade" é explicada porque a justiça corresponde a uma orientação "para com o outro",55 o "dever" porque o outro pode esperar que o justo seja realizado, ${ }^{56}$ e "igualdade" porque ela deve ser proporcional tanto no sentido aritmético (2=2) quanto no geométrico (3:2=6:4). ${ }^{57}$ Diz Finnis: «Ao considerar estes três elementos, entendidos desse modo, como necessários e suficientes para que uma valoração seja uma valoração em termos de justiça, estou tratando de dar-lhe suficiente precisão para que ele seja útil a uma análise da razoabilidade prática, bem como suficiente amplitude para que seja digno de sua clássica e popular proeminência nesta análise». ${ }^{58}$ Desse modo, «as exigências da justiça são as implicações concretas da exigência básica da razoabilidade prática segundo a qual um tem de favorecer e promover o bem-comum de suas próprias comunidades». ${ }^{59}$

Para Finnis "Direito Natural" é sinônimo de "direitos humanos". ${ }^{60}$ Segundo seu raciocínio, falar em "direitos" é uma forma de se falar em razoabilidade prática e bemcomum.

\footnotetext{
${ }_{55}$ FINNIS, John Mitchell. Natural law and natural righs. Oxford: Oxford University Press, 1980. p. 161 e 191.

${ }^{56}$ Id. Ibid., p. 162 e 193.

${ }^{57}$ Id. Ibid., p. 163 e 193.

${ }^{58}$ Id. Ibid.

${ }^{59}$ Id. Ibid., p. 164 e 194.

${ }^{60}$ Id. Ibid., p. 198 e 227.
} 
Neste contexto, os "direitos humanos" constituem nada mais do que «uma forma de expressar virtualmente todas as exigências da razoabilidade prática», pois eles «classificam e expressam as exigências da justiça», por esse motivo que eles, os direitos humanos, representam «uma forma de se esboçar os contornos do bem comum (...) uma expressão enfática do que está implícito no termo bem-comum». ${ }^{61}$ Isto significa que Finnis entende que operar segundo a "razoabilidade prática" implica em atuar com justiça para a construção do bem-comum, de tal maneira que a idéia de "justiça” (no sentido de agir com justiça) é um dos aspectos das instituições informadas pelos princípios básicos.

Em suma, as exigências de justiça se expressam atualmente na linguagem dos direitos humanos.

Considerando o que foi dito no item 4.3., a garantia desses direitos humanos na "vida da comunidade" cabe à autoridade, pois a esta cumpre realizar os atos de coordenação. Uma autoridade que se legitima pela necessidade, portanto, de uma ordem em comunidade.

10. "Direitos" e "direitos absolutos"

Para precisar sua noção de "direitos", utilizada, por exemplo, na expressão “direitos humanos", Finnis parte da classificação de Wesley H. Hohfeld, presente no escrito "Conceitos Jurídicos Fundamentais".

Segundo entende Finnis, para compreender os "direitos humanos" importa as duas primeiras análises de direitos de Hohfeld, isto é, a dos direitos no sentido de "pretensão" e "privilégios" (ou liberdades). Aqui, destaca que as liberdades podem ounão estar protegidas juridicamente com “pretensões". As "pretensões", assim, expressam a possibilidade de reclamar que cessem os obstáculos à realização de algo.

Deve-se consignar, ainda, que Finnis procura evidenciar que as relações de “direitos" são sempre relações de "três termos" - e não de "dois" como às vezes se vê sugerido. São eles: uma pessoa; certo tipo de ato; e uma outra pessoa. O ponto central da ponderação de Finnis é que a noção de "direitos" não é uma eleição pessoal, muito menos um benefício pessoal, senão «os aspectos básicos do florescimento humano». ${ }^{62}$

Pontua Finnis, por conseguinte, que «a gramática moderna dos direitos proporciona uma forma de expressar virtualmente todas as exigências da razoabilidade

\footnotetext{
${ }_{61}$ FINNIS, John Mitchell. Natural law and natural righs. Oxford: Oxford University Press, 1980. p. 198-199 e 227-228.

${ }^{62}$ FINNIS, John Mitchell. The rational strength of christian morality. London: Netherhall House, 1974. p. 5-8.
} 
prática». ${ }^{63} \mathrm{E}$ mais, que «o vocabulário moderno dos direitos são um instrumento multifacetado para expressar e afirmar as exigências e outras implicações de uma relação de justiça desde o ponto de vista da(s) pessoa(s) que se beneficia(m) desta relação». ${ }^{64}$ Objetivando assimilar adequadamente essa "gramática", Finnis realiza um resumo histórico de sua significação semântica. Assim, recorda como dos jurisconsultos romanos até Santo Tomás de Aquino "ius" significava, antes de tudo, "a realidade justa”, isto é, os atos, as omissões ou estado de coisas considerados como objeto das relações de justiça. ${ }^{65}$

Afirma, ainda, que a partir de Suarez e Grotius esta significação primeira de "ius" se modifica e passa a se referir a "faculdade" ou "qualidade" moral que possui o sujeito de direito, a qual é resumida em definitivo em uma "pretensão" ou em uma "liberdade". 66

Assinala assim que «Esta mudança de perspectiva poderia ser tão drástica para tirar o titular do direito, e seu direito, completamente da relação jurídica que está fixada pela lei (moral ou positiva) e que funda o "ius" no sentido de Tomás de Aquino: "o que é justo"» ${ }^{67}$. Foi dessa maneira que Hobbes pretendeu sustentar que «um homem possui o máximo de direitos quando se encontra em "estado de natureza"». ${ }^{68}$

Mas entende Finnis que «quando examinamos esta lista nos damos conta de que o que importa na moderna concepção dos "manifestos" direitos humanos» é «simplesmente uma forma de esboçar os contornos do bem comum, os distintos aspectos do bem-estar individual na comunidade. O que a referência aos direitos aporta neste esboço é simplesmente uma expressão enfática do que está implícito no termo bemcomum, a saber; que o bem-estar de todos e de cada um, em cada um de seus aspectos básicos, deve ser considerado e favorecido a todo o momento pelos responsáveis pela coordenação do bem-comum». ${ }^{69}$

Desse ponto nosso Autor questiona se é possível haver "direitos humanos absolutos". A isso responde desenganadamente que sim, porque uma das exigências da razoabilidade prática é que resulta sempre irracional optar diretamente contra qualquer valor básico, porque os valores básicos não são abstrações, mas aspectos do verdadeiro bem

\footnotetext{
${ }^{63}$ FINNIS, John Mitchell. Natural law and natural righs. Oxford: Oxford University Press, 1980. p. 198 e 227.

${ }^{64}$ Grifos do original. FINNIS, John Mitchell. Natural law and natural righs. cit., p. 205-206 e 234.

${ }^{65}$ Id. Ibid., p. 206 e 235.

66 Id. ibid.

${ }^{67}$ Id. Ibid., p. 207 e 236.

${ }^{68}$ Id. ibid., p. 207-208 e 237.

${ }^{69}$ Id. Ibid., p. 215 e 243.
} 
aos indivíduos de "carne e osso" ${ }^{70}$ Com respeito à identificação desses direitos absolutos, Finnis registra breve enumeração: o mais evidente é o direito de não ser privado da própria vida diretamente como um meio à consecução de determinados fins; mas, dentre eles também inclui o de não poder ser privado da capacidade de procriar.

\section{O "Império do Direito"}

Para Finnis o direito apresenta cinco características formais que tanto mais se realizam quando oito desiderata são cumpridos. Na realidade, a convergência entre esses planos é que torna possível, segundo nosso autor, a idéia de "Estado de Direito", pois "Estado de Direito" é tradução para «um estado de coisas em que um sistema jurídico está em bom estado», ou seja, um Estado que é guiado pela combinação de exigências de segurança jurídica com as exigências do bem-comum, de maneira que é um Estado conforme a justiça.

Para todos os efeitos, estas são as cinco características formais do direito aos olhos de Finnis: ${ }^{71}$

1. "Regras de coação". Segundo Finnis, o direito é necessariamente coativo: primeiramente através de sanções punitivas; secundariamente mediante intervenções restritivas, pois o castigo tanto atua como incentivo para que se aja conforme ao direito como para restaurar o equilíbrio de vantagens entre aquele que viola e aquele que respeita a lei;

2. "O direito regula sua própria criação". O direito atribui previsibilidade às interações humanas utilizando-se de regras e instituições que ele mesmo formula;

3. "As normas jurídicas permanecem no tempo". Afirma Finnis que as normas jurídicas se caracterizam por, uma vez criadas, permanecerem válidas até o exaurimento do seu propósito ou sua revogação;

4. "As normas jurídicas regulam a atuação dos indivíduos, podem modificar a extensão e a aplicação de regras". Ou seja, as regras jurídicas também organizam a atuação privada na constituição de padrões de conduta;

5. "O direito assume a fícção de previsibilidade total". Conforme Finnis, é comum a presença do postulado conforme o qual os atos jurídicos passados prevêem os problemas de coordenação social.

\footnotetext{
${ }^{70}$ FINNIS, John Mitchell. Natural law and natural righs. Oxford: Oxford University Press, 1980. p. 223-225 e 252-253.

${ }^{71}$ Id. Ibid, p. 268-269 e 296-298.
} 
Por sua vez, estes são os oito desiderata: 1) as regras do Direito devem ser prospectivas e não-retroativas; 2) as regras devem estatuir o que é possível de se fazer ou realizar; 3) suas regras devem ser promulgadas; 4) elas devem ser claras; 5) coerentes entre si; 6) suficientemente estáveis; 7) as ordens que regulam as situações de comportamento devem resultar de orientações gerais; e 8) as autoridades devem aplicar o Direito coerentemente e segundo o seu teor.

Tudo considerado, diz Finnis, o "Império do Direito" é uma «virtude da interação e da comunidade humanas». ${ }^{72}$

A partir dessas referências, apresenta sua "definição" ou o "significado focal” de Direito: «o termo 'Direito'tem sido usado em seu significado focal para referir-se primariamente a regras produzidas, de acordo com regras jurídicas regulativas, por uma autoridade determinada e efetiva (ela mesma identificada e, normalmente, constituída como instituição mediante regras jurídicas) para uma comunidade “completa”, e apoiada por sanções em conformidade com disposições de instituições julgadoras guiadas por regras, estando esta conjugação de regras e instituições direcionada a resolver razoavelmente qualquer dos problemas de coordenação da comunidade (e a ratificar, tolerar, regular, ou deixar sem efeito as soluções coordenadoras precedentes de quais quer outras instituições ou fonte de normas) para o bem-comum desta comunidade, segundo uma maneira e forma em si mesma adaptada a esse bem-comum por características como a especificidade, a minimização da arbitrariedade, e a manutenção da reciprocidade entre os destinatários do direito, tanto de uns em relação aos outros como em suas relações com as autoridades legitimas». ${ }^{73}$

\section{Conclusão}

Finnis, depois de ter confessado suas raízes analíticas, disse que em determinado momento suspeitou que poderia haver nas teorias do Direito Natural algo mais que superstição e obscuridade.

Para desenvolver este insight, pôs-se a afirmar que a teoria de Santo Tomás de Aquino foi pouco compreendida, e mais: que a acusação comum às teorias jusnaturalistas de violarem a "Lei de Hume" não passava — ao menos no caso de Aquino — de um

\footnotetext{
${ }^{72}$ FINNIS, John Mitchell. Natural law and natural righs. Oxford: Oxford University Press, 1980. p. 269-270 e 300.

${ }^{73}$ Id. Ibid., p. 276-277 e 304.
} 
engano. Assim, questionou as análises "caricaturais" desenvolvidas por inúmeros autores e procurou, a partir desse ponto, fornecer embasamento mais robusto.

Conforme teoriza, há determinados conteúdos morais que, longe de derivarem da metafísica ou de inferências empíricas mal-sustentadas são auto-evidentes. Esses valores auto-evidentes, os quais Finnis denomina um tanto erraticamente de "bens básicos", "princípios", “formas de florescimento humano", "bens humanos” ou, tãosomente, de "valores" ou "bens", segundo entende podem ser alcançados pelo emprego da inteligência, de tal modo que eles são, inclusive, pré-morais.

Sendo assim, o teórico que desejar compreendê-los adequadamente deve assumir o ponto de vista interno, isto é; do participante, pois apenas assim ele terá condições para detectar corretamente o seu objeto de estudo, qual seja; o "caso central". Dessa forma, o estudioso deve eleger a atitude social que assume o Direito como uma instituição que merece respeito e obediência. Este ponto de vista moral é o ponto de vista da "razoabilidade prática". "Razoabilidade prática" corresponde à uma perspectiva de ação e decisão. Com isso, nosso autor não exclui o "injusto" de sua apreciação, porquanto ele, como caso "periférico" de Direito, permite mais bem compreender o que é o Direito. Por isso que o Direito, mesmo que injusto, continua sendo Direito em sua teoria, embora isso não signifique que deva ser obedecido.

Tudo considerado, o pano de fundo de Finnis é uma preocupação humanista para com o homem o que pode ser notado no papel pragmático dos "bens básicos" de corresponderem aos meios para que o homem se desenvolva como "ser humano". Portanto, quando faz referência aos "bens básicos" nosso Autor ocupa-se com o que é preciso ou necessário para que haja o florescimento humano, daí o caráter que assina de pré-moral, pré-político e pré-jurídico que eles possuem. Porque sendo anteriores a todos esses fatores e auto-evidentes, o papel da autoridade é coordenar esses bens em comunidade. Para que isso seja factível, Finnis fornece uma lista para a "razoabilidade prática" ser uma "realidade", de maneira que ela funcione como instrumento de viabilização para que se possam estabelecer relações dignas de obediência entre comunidade e autoridade.

Conforme se depreende desta quadratura, as noções de "bem-comum", “justiça”, "direitos humanos" constituem o conteúdo valorativo da compreensão de direito de Finnis, enquanto a repercussão deles frente às leis injustas demarca a operacionalidade da oposição que se pode oferecer quando há ofensa a eles. Nesse passo, procura deixar claro que a autoridade política deve pautar-se por esta lista tendo em vista que, conquanto ela possua a capacidade de coordenar a vida em sociedade, a obediência ao que estabelece depende do vínculo do estabelecido por ela em relação com o bem-comum. Aliás, não 
é por outra razão que as sanções são apresentadas por nosso Autor como "instrumentos de educação" e de "compensação", já que o delinqüente ao ser punido o é para aprender com o seu erro ao mesmo tempo em que, através da punição aqueles que cumprem os preceitos jurídicos não se vêem postos para trás considerando-se a vantagem injusta do recalcitrante.

Enfim, Finnis formula um jusnaturalismo "peculiar" no qual no lugar da natureza coloca-se o "razoável" e, do razoável, o sustentáculo dos "direitos humanos".

São Paulo, setembro de 2007.

Referências

FINNIS, John Mitchell. Natural law and natural rights. Oxford: Oxford University Press, 1980. . Natural law and natural rights. Tradução Cristóbal Orrego Sánchez (Ley natural y derechos naturales). Buenos Aires: Abeledo-Perrit, 2000.

. Fundamental of ethics. Georgetown: Georgetown University Press, 1983.

; GRISEZ, Germaine; BOYLE, Joseph. Nuclear deterrence, morality and realism. Oxford: Clarendom Press, 1987.

FINNIS, John Mitchell. The rational strength of christian morality. London: Netherhall House, 1974.

TOMÁS DE AQUINO, Santo. Summa Theologica. Madrid: Editorial Catolica, 1947-1960. 